\title{
Clinical and Microbiological Characterization of Patients with Generalized Aggressive Periodontitis
}

\author{
Caracterización Clínica y Microbiológica de Pacientes \\ con Periodontitis Agresiva Generalizada
}

\author{
Carlos Martín Ardila Medina; Clara Lina Salazar \& Isabel Cristina Guzmán Zuluaga
}

ARDILA, M. C. M.; SALAZAR, C. L. \& GUZMÁN, Z. I. C. Clinical and microbiological characterization of patients with generalized aggressive periodontitis. Int. J. Odontostomat., 8(3):371-376, 2014.

ABSTRACT: Aggressive periodontitis embraces a cluster of promptly advancing forms of periodontal disease that appear in otherwise clinically healthy patients. The objective of this investigation was to characterize clinical and microbiologically a sample of Colombian patients with Generalized Aggressive Periodontitis (GAgP). In this cross sectional study, 40 subjects $\leq 30$ years with GAgP who attended the dental clinics of the Universidad de Antioquia in Medellín, Colombia were invited to participate from February 2012 to August 2013. Microbial sampling on periodontitis patients was performed on pockets $\geq 5 \mathrm{~mm}$. The deepest six pockets were selected for sampling. The samples were analyzed using microbial culture techniques. Porphyromonas gingivalis and Prevotella spp. were both detected at high levels. In bivariate analysis a strong association between the periodontal parameters and presence of all microorganisms studied was observed (P<0.0001). Similarly, the logistic regression analysis showed a significant association among periodontopathogens. The most relevant was observed between P. gingivalis and Tanerella forsythia ( $\mathrm{OR}=4.8$ ). A high proportion of sites $\geq 6 \mathrm{~mm}(869 \mathrm{sites;} 49.95 \%)$ was observed. In conclusion, $P$. gingivalis was more intensely related with aggressive periodontal disease, while the occurrence of Aggregatibacter actinomycetemcomitans was lower than that of $P$. gingivalis.

KEY WORDS: aggressive periodontitis, porphyromonas gingivalis, aggregatibacter actinomycetemcomitans, periodontal microbiology.

\section{INTRODUCTION}

Aggressive periodontitis embraces a cluster of promptly advancing forms of periodontal disease that appear in otherwise clinically healthful patients. Individuals with aggressive periodontitis are often diagnosed as having a localized form or a generalized form of disease. The occurrence of clinical inflammation in generalized aggressive periodontitis (GAgP) emerges to be comparable to that perceived in chronic periodontitis. In GAgP condition, age of commencement and familial aggregation are significant supplementary criteria for either diagnosis or classification (Teughels et al., 2014). Patients with $\geq 3$ $\mathrm{mm}$ of clinical attachment loss in four or more teeth and in whom at least two of the affected teeth were second molars, cuspids or premolars, have been classified as having the generalized form of aggressive periodontitis. Equally, elevated proportions of Aggregatibacter actinomycetemcomitans and, in some populations, of Porphyromonas gingivalis have been presented among potential secondary features of generalized forms of aggressive periodontitis, as stated previously (Armitage, 1999).

As there can be noticeable dissimilarities in the amounts of periodontal organisms among diverse populations, the colonization of young patients with these two gram-negative species, as well as with other periodontitis-associated bacteria, depends on the occurrence of the organisms in an indicated population (Könönen \& Müller, 2014). Susin et al. (2014) depicted that the countries in South America comprise a diverse racial composition, with various nations, such as Chile

\footnotetext{
* Chief of Stomatology Group Research, Titular Professor, School of Dentistry, Universidad de Antioquia, Medellín, Colombia.

* Microbiologist, Professor, Universidad de Antioquia, Medellín, Colombia.

${ }^{* * *}$ Periodontist, Associate Professor, Universidad de Antioquia, Medellín, Colombia.
} 
and Argentina, including mostly a Caucasian population, whereas other countries, such as Brazil, involve a mixed-race population, concluding that the prevalence of aggressive periodontitis varies significantly between different geographic locations and between different race/ethnicities. Accordingly, the prevalence of GAgP in Latin America has been estimated between $0.32 \%$ in Chile, and $5.5 \%$ in Brazil in representative samples of their target populations (Lopez et al., 1996; Susin \& Albandar, 2005). A lack of information on the epidemiology of this disease in many parts of the world is emphasized (Susin et al.).

As pointed out by Susin et al., investigations of aggressive periodontitis in high-risk populations are imperative and could offer fundamental data on the determinants of this disease, and this knowledge is required in order to create successful health-promotion processes.

To our knowledge no studies have looked at the microbiology and clinical characterization of patients with GAgP in Medellin, Colombia. Bearing in mind the specific ethnic nature of the disease, the objective of this investigation was to characterize clinical and microbiologically a sample of Colombian patients with GAgP.

\section{MATERIAL AND METHOD}

In this cross sectional study, 40 subjects $\leq 30$ years with GAgP who attended the dental clinics of the Universidad de Antioquia in Medellín, Colombia were invited to participate from February 2012 to August 2013. Informed and written consent was obtained from each participant. The study design was approved by the Ethics Committee on Human Research of the School of Dentistry of the Universidad de Antioquia according to the Declaration of Helsinki on experimentation involving human subjects.

The diagnosis of GAgP was made based on criteria defined at the workshop sponsored by the American Academy of Periodontology (Armitage). Subjects were $\leq 30$ years of age, minimum of six permanent teeth, including incisors and/or first molars, with at least one site each with probing depth (DP) and clinical attachment level $(\mathrm{CAL}) \geq 5 \mathrm{~mm}$ and a minimum of six teeth other than first molars and incisors with at least one site each with PD and CAL $\geq 5 \mathrm{~mm}$. During the anamneses, the subjects were asked if they had at least one other member of the family presenting or with history of periodontal disease in order to assess the familial aggregation. Exclusion criteria included diabetes, cardiovascular disease, immunological disorders or any other systemic disease that could alter the course of periodontal disease. Pregnant or nursing women, smoking, consumption of systemic antimicrobials or anti-inflammatory drugs in the last six months, and periodontal therapy during the last six months also served as exclusion criteria.

Medical history and clinical and radiographic examination were conducted for each patient. A trained and calibrated clinician performed all clinical examinations. At each monitoring visit, visible plaque (0/1), bleeding on probing (BOP) (0/1), PD (in mm) and CAL (in $\mathrm{mm}$ ) were measured at six sites per tooth (mesiobuccal, buccal, distobuccal, distolingual, lingual and mesiolingual) in all teeth excluding third molars (a calibrated standard probe was used; UNC-15, HuFriedy, Chicago, IL).

The intra-examiner reproducibility was assessed before and during the study. The intra-class correlation coefficients for mean PD and CAL were 0.92 and 0.91 , respectively; the intra-evaluator kappa index was in the range $0.80-0.92$.

Microbial Sampling. Microbial sampling on periodontitis patients was performed on pockets $\geq 5$ $\mathrm{mm}$. The deepest six pockets were selected for sampling. After removing supragingival plaque with curettes and isolating the area with cotton pellets, the paper points (Maillefer, Ballaigues, Switzerland) were inserted into each periodontal pocket for 20 seconds. The paper points were transferred to a test tube containing $1 \mathrm{ml}$ of the VMGA III transport medium under anaerobic conditions and immediately sent to the microbial laboratory. Generally, isolation of microorganisms was carried out by methods previously reported by D'Ercole et al. (2008). The samples were analyzed using microbial culture techniques for the presence of periodontopathic bacteria according to Slots (1986). All samples were processed in $\leq 24$ hours at room temperature and immediately incubated in $\mathrm{CO} 2$ and anaerobic culture systems. Brucella blood agar medium was incubated at $35^{\circ} \mathrm{C}$ in an anaerobic jar for 7 days. The trypticase-soy with serum, bacitracin, and vancomycin medium was incubated in 10\% CO2 in air at $37^{\circ} \mathrm{C}$ for 4 days. Presumptive identification was performed according to the methods described (Slots; Slots \& Reynolds, 1982) and using a commercial identification micromethod system (RapID ANA, Remel, 
Norcross, GA). Total viable counts (TVC) were defined as the total number of colony-forming units obtained on non-selective media plates. Species found on selective media were enumerated and their percentage of TVC was calculated. Each patient provided a pooled subgingival plaque sample. Equal numbers of isolates were used from each subject.

Statistical Analysis. Data were entered into an Excel (Microsoft office 2007) database and were proofed for entry errors. The subject was the unit for the basic statistical analysis. Mean values \pm standard deviation (SD) and the proportions of sites within various categories of scoring units were calculated for data description. Normal distribution of continuous variables was verified with the Kolmogorov-Smirnov test. Categorical data were analyzed with the X2 test. Data concerning sites with PD $\geq 6 \mathrm{~mm}$ were analyzed separately with the site as the observational unit. Microbiological data were analyzed with the subject as the observational unit. Associations between periodontal pathogens were assessed by logistic regression analysis. The OR and corresponding 95\% confidence intervals were calculated for each microorganism. The significance level was set at 0.05 for all tests. All data handling and statistical testing were performed with a software package (SPSS, Statistical Package for the Social Sciences, version 18, Chicago, IL).

\section{RESULTS}

Table I. Demographic characteristics and periodontal parameters of the patients with periodontitis.

\begin{tabular}{|c|c|c|}
\hline \multicolumn{2}{|c|}{ Parameter } & $\begin{array}{l}\text { Periodontitis subjects } \\
\qquad(n=40)\end{array}$ \\
\hline \multicolumn{2}{|c|}{ Age (years $\pm S D$ ) } & $27 \pm 2.8$ \\
\hline \multirow{2}{*}{ Gender } & $\%$ Female & $57.5 \%$ \\
\hline & $\%$ Male & $42.5 \%$ \\
\hline \multicolumn{2}{|c|}{$P D(m m \pm S D)$} & $5.3 \pm 4.3$ \\
\hline \multicolumn{2}{|c|}{$\mathrm{CAL}(\mathrm{mm} \pm \mathrm{SD})$} & $5.9 \pm 4.9$ \\
\hline \multicolumn{2}{|c|}{ Plaque } & $44 \%$ \\
\hline \multicolumn{2}{|l|}{ BOP } & $45 \%$ \\
\hline
\end{tabular}

$\mathrm{SD}=$ Standard Deviation
Sixty-eight subjects were assessed for their eligibility before entering the study. Of these, 28 subjects were excluded because they did not meet the inclusion criteria. Table I depicts the baseline clinical and demographic characteristics of the 40 patients studied. A higher number of women were observed.

The proportions of subjects positive for investigated species are presented in Table II. Porphyromonas gingivalis and Prevotella spp. were both detected at high levels. On the other hand, in bivariate analysis a strong association between the periodontal parameters and presence of all microorganisms studied was observed $(P<0.0001)$. Similarly, the logistic regression analysis showed a significant association among periodontopathogens (Table III). The most relevant was observed between $P$. gingivalis and Tanerella forsythia $(\mathrm{OR}=4.8)$.

Finally, a high proportion of sites $\geq 6 \mathrm{~mm}$ (869 sites; $49.95 \%$ ) was observed.

Table II. Number of subjects positive for Aggregatibacter actinomycetemcomitans (A.a), Porphyromonas gingivalis (P.g), Tanerella forsythia (T.f), Prevotella spp., and Fusobacterium nucleatum (F.n).

\begin{tabular}{lcc}
\hline Microorganisms & Number & \% \\
\hline A.a & 13 & 32.5 \\
P.g & 27 & 67.5 \\
T.f & 9 & 22.5 \\
Prevotella ssp. & 25 & 62.5 \\
F.n & 19 & 47.5 \\
\hline
\end{tabular}

\section{DISCUSSION}

Aggressive periodontitis is a relatively rare inflammatory condition, mostly seen in young individuals, characterized by severe and rapid breakdown of the periodontium (Armitage). For the above reason, the microbiology and clinical characterization of patients with GAgP is very important. To our knowledge, the present study is the

Table III. Associations among periodontal pathogens evaluated.

\begin{tabular}{lccccccccc}
\hline \multirow{2}{*}{ Microorganism } & \multicolumn{4}{c}{ A. actinomycetemcomitans } & \multicolumn{3}{c}{ T. forsythia } & \multicolumn{2}{c}{$\boldsymbol{F}$. nucleatum } \\
\cline { 2 - 11 } & OR & $\mathbf{9 5 \%}$ IC & $\boldsymbol{P}$ value & OR & $\mathbf{9 5 \%}$ IC & $\boldsymbol{P}$ value & OR & $\mathbf{9 5 \%}$ IC & $\boldsymbol{P}$ value \\
\hline$P$. gingivalis & 2.1 & $1.4-2.9$ & $<0.0001$ & 4.8 & $3.1-7.5$ & $<0.0001$ & 3.3 & $2.3-4.7$ & $<0.0001$ \\
\hline
\end{tabular}


first that has evaluated the clinical and microbiological characteristics in a sample of Colombian patients with GAgP.

The composition of the subgingival microbiota among subjects with GAgP usually differs considerably (Teles et al., 2010). In recognized disease and in exacting, after the extent of periodontal lesions, the microbiota might turn into much more complex and soon may resemble that of generalized chronic periodontitis with microorganisms of the red complex apparently dominating the subgingival ecosystems (Könönen \& Müller). Thus, the results from this study showed that $P$. gingivalis and Prevotella spp. were isolated frequently among patients with GAgP. In GAgP, the occurrence of identification of $P$. gingivalis varied between $62 \%$ and $100 \%$ in different populaces (Takeuchi et al., 2003; Gajardo et al., 2005). Comparably, this microorganism was the most frequently found $(67.5 \%)$ in the currently studied population. Equally, P. gingivalis showed a statistical association with higher PD, CAL and BOP similar to the findings reported by other investigators (Lafaurie et al., 2007). Because $P$. gingivalis can be detected in almost all the patients with GAgP, the question arises as to whether the $P$. gingivalis detected in patients with GAgP is a highly virulent strain (Feng et al., 2014).

The levels of Aggregatibacter actinomycetemcomitans reported in periodontitis also vary among populations. In GAgP, $A$. actinomycetemcomitans varied between $3 \%$ and $53 \%$ among Europeans and Americans (Kamma et al., 1994; Gainet et al., 1999). In concordance, this study demonstrated that the presence of $A$. actinomycetemcomitans was $32.5 \%$. Similar to $P$. gingivalis, this microorganism also showed statistical association with higher PD, CAL and BOP, corroborating the results of Takeuchi et al. At this time, A. actinomycetemcomitans is mostly viewed as opportunistic bacteria of the resident oral microbiota, while its specific JP2 clone, representing serotype b, has properties of a true exogenous pathogen (Haubek, 2010).

In the present study, T. forsythia was also a predominant periodontopathogens in GAgP, and in concordance with this study, it has been associated with the severity of clinical parameters including PD, CAL and BOP (Kamma et al.)

Although, Prevotella spp. has not been investigated extensively, it has also been associated with GAgP in some investigations (Lopez et al.; Kamma et al.; Feng et al.), and our results coincide with these previous reports. Similarly, Fusobacterium nucleatum has also been associated with GAgP in a previous study (Lee et al., 2003). Our results show a strong association between the periodontal pathogens identified and GAgP. Is important to note that these data are quantitative, and they are showing presence and quantities of microorganisms, becoming relevant information. In the present study, pooled samples of six affected sites per patient were analyzed by bacterial culture. While thoughts vary as to whether microbiological data should be evaluated on individual sites or using the patient as the study unit, here we selected the second method based on the principle that patients are being treated as a whole. Gajardo et al., have treated similar establishment.

Coaggregation between microorganisms plays a key role in the colonization of the gingival crevice and the organization of periodontopathic biofilms. In this study, the logistic regression analysis showed a significant association among $P$. gingivalis, $T$. forsythia, $F$. nucleatum and $A$. actinomycetemcomitans. It has been shown that some members of the red complex coaggregate strongly in vitro and one species of the complex may produce growth factors required by another in that complex.

In the present investigation a high proportion of sites $\geq 6 \mathrm{~mm}$ (869 sites, $49.95 \%$ ) was observed. Similar results have been presented broadly in studies treating aggressive periodontitis (Aimetti et al., 2012; Mestnik et al., 2010).

In conclusion, taken together, the results showed here denote that $P$. gingivalis was more intensely related with aggressive periodontal disease, while the occurrence of $A$. actinomycetemcomitans was lower than that of $P$. gingivalis. Investigations are necessary to further examine the function of particular $A$. actinomycetemcomitans strains and other microbial species in the pathogenesis of aggressive periodontitis.

\section{ACKNOWLEDGEMENTS}

The School of Dentistry and the Microbiology Laboratory of the School of Microbiology of the Universidad de Antioquia supported this study. The authors acknowledge the support of Diana Molina in the processing of microbiological samples. 
ARDILA, M. C. M.; SALAZAR, C. L. \& GUZMÁN, Z. I. C. Caracterización clínica y microbiológica de pacientes con periodontitis agresiva generalizada. Int. J. Odontostomat., 8(3):371-376, 2014.

RESUMEN: La periodontitis agresiva abarca un conjunto de variedades de la enfermedad periodontal que avanzan rápidamente en pacientes clínicamente sanos. El objetivo de esta investigación fue caracterizar clínica y microbiológicamente una muestra de pacientes colombianos con periodontitis agresiva generalizada (PAG). En este estudio transversal, la muestra se conformó con 40 sujetos mayores de 30 años con PAG, que asistieron a las clínicas dentales de la Universidad de Antioquia en Medellín, Colombia, y fueron invitados a participar del estudio desde febrero de 2012 hasta agosto de 2013. El muestreo microbiano en pacientes con periodontitis se realizó en bolsas periodontales $\geq 5 \mathrm{~mm}$. Los seis bolsas periodontales más profundos fueron seleccionadas para el muestreo. Las muestras se analizaron usando técnicas de cultivo microbianos. Porphyromonas gingivalis y Prevotella spp. fueron detectadas en niveles altos. En el análisis bivariado se observó una fuerte asociación entre los parámetros periodontales y la presencia de los microorganismos estudiados $(P<0,0001)$. Del mismo modo, el análisis de regresión logística mostró una asociación significativa entre los periodontopatógenos. La asociación más relevante se observó entre $P$. gingivalis y Tanerella forsythia $(\mathrm{OR}=4,8)$. Se observó además, una alta proporción de los sitios $\geq 6 \mathrm{~mm}$ (49,95\%, 869 sitios). En conclusión, $P$. gingivalis fue más intensamente relacionada con la enfermedad periodontal agresiva, mientras que la aparición de Aggregatibacter actinomycetemcomitans fue mucho menor que la de $P$. gingivalis.

PALABRAS CLAVE: periodontitis agresiva, Porphyromonas gingivalis, Aggregatibacter actinomycetemcomitans, microbiología periodontal.

\section{REFERENCES}

Aimetti, M.; Romano, F.; Guzzi, N. \& Carnevale, G. Full-mouth disinfection and systemic antimicrobial therapy in generalized aggressive periodontitis: a randomized, placebo-controlled trial. J. Clin. Periodontol., 39(3):28494, 2012.

Armitage, G. C. Development of a classification system for periodontal diseases and conditions. Ann. Periodontol., 4(1):1-6, 1999.

D'Ercole, S.; Catamo, G.; Tripodi, D. \& Piccolomini, R. Comparison of culture methods and multiplex PCR for the detection of periodontopathogenic bacteria in biofilm associated with severe forms of periodontitis. New Microbiol., 31(3):383-91, 2008.

Feng, X.; Zhang, L.; Xu, L.; Meng, H.; Lu, R.; Chen, Z.; Shi, D. \& Wang, $X$. Detection of eight periodontal microorganisms and distribution of Porphyromonas gingivalis fimA genotypes in Chinese patients with aggressive periodontitis. J. Periodontol., 85(1):150-9, 2014.

Gainet, J.; Dang, P. M.; Chollet-Martin, S.; Brion, M.; Sixou, M.; Hakim, J.; Gougerot-Pocidalo, M. A. \& Elbim, C. Neutrophil dysfunctions, IL-8, and soluble L-selectin plasma levels in rapidly progressive versus adult and localized juvenile periodontitis: variations according to disease severity and microbial flora. J. Immunol., 163(9):50139,1999 .

Gajardo, M.; Silva, N.; Gómez, L.; León, R.; Parra, B.; Contreras, A. \& Gamonal, J. Prevalence of periodontopathic bacteria in aggressive periodontitis patients in a Chilean population. J. Periodontol., 76(2):289-94, 2005.

Haubek, D. The highly leukotoxic JP2 clone of Aggregatibacter actinomycetemcomitans: evolutionary aspects, epidemiology and etiological role in aggressive periodontitis. APMIS (Suppl. 130):1-53, 2010.

Kamma, J. J.; Nakou, M. \& Manti, F. A. Microbiota of rapidly progressive periodontitis lesions in association with clinical parameters. J Periodontol., 65(11):1073-8, 1994.

Könönen, E. \& Müller, H. P. Microbiology of aggressive periodontitis. Periodontol. 2000, 65(1):46-78, 2014.

Lafaurie, G. I.; Contreras, A.; Barón, A.; Botero, J.; MayorgaFayad, I.; Jaramillo, A.; Giraldo, A.; González, F.; MantiIla, S.; Botero, A.; Archila, L. H.; Díaz, A.; Chacón, T.; Castillo, D. M.; Betancourt, M.; Del Rosario-Aya, M. \& Arce, R. Demographic, clinical, and microbial aspects of chronic and aggressive periodontitis in Colombia: a multicenter study. J. Periodontol., 78(4):629-39, 2007.

Lee, J. W.; Choi, B. K.; Yoo, Y. J.; Choi, S. H.; Cho, K. S.; Chai, J. K. \& Kim, C. K. Distribution of periodontal pathogens in Korean aggressive periodontitis. J. Periodontol., 74(9):1329-35, 2003.

López, N. J.; Mellado, J. C. \& Leighton, G. X. Occurrence of Actinobacillus actinomycetemcomitans, Porphyromonas gingivalis and Prevotella intermedia in juvenile periodontitis. J. Clin. Periodontol., 23(2):101-5,1996. 
Mestnik, M. J.; Feres, M.; Figueiredo, L. C.; Duarte, P. M.; Lira, E. A. \& Faveri, M. Short-term benefits of the adjunctive use of metronidazole plus amoxicillin in the microbial profile and in the clinical parameters of subjects with generalized aggressive periodontitis. J. Clin. Periodontol., 37(4):353-65, 2010.

Slots, J. Rapid identification of important periodontal microorganisms by cultivation. Oral Microbiol. Immunol., 1(1):48-57,1986.

Slots, J. \& Reynolds, H. S. Long-wave UV light fluorescence for identification of black-pigmented Bacteroides spp. J. Clin. Microbiol., 16(6):1148-51, 1982.

Susin, C.; Haas, A. N. \& Albandar, J. M. Epidemiology and demographics of aggressive periodontitis. Periodontol. 2000, 65(1):27-45, 2014.

Susin, C \& Albandar, J. M. Aggressive periodontitis in an urban population in southern Brazil. J. Periodontol., 76(3):468-75, 2005.

Takeuchi, Y.; Umeda, M.; Ishizuka, M.; Huang, Y. \& Ishikawa, I. Prevalence of periodontopathic bacteria in aggressive periodontitis patients in a Japanese population. J. Periodontol., 74(10):1460-9, 2003.

Teles, R. P.; Gursky, L. C.; Faveri, M.; Rosa, E. A.; Teles, F. R.; Feres, M.; Socransky, S. S. \& Haffajee, A. D. Relationships between subgingival microbiota and GCF biomarkers in generalized aggressive periodontitis. $J$. Clin. Periodontol., 37(4):313-23, 2010.

Teughels, W.; Dhondt, R.; Dekeyser, C. \& Quirynen, M. Treatment of aggressive periodontitis. Periodontol. 2000, 65(1):107-33, 2014.
Correspondence to:

Carlos M. Ardila

Ph.D in Epidemiology

Chief of Stomatology Group Research

School of Dentistry

Universidad de Antioquia

Calle 70 No. $52-21$

Medellín

COLOMBIA

Email: martinardila@gmail.com

Received: 09-06-2014

Accepted: 08-08-2014 